\title{
PROFIL KESULITAN BELAJAR SISWA SMP DALAM MEMECAHKAN MASALAH SOAL SISTEM PERSAMAAN LINEAR DUA VARIABEL
}

\section{LEARNING DIFFLICULTIES OF JUNIOR HIGH SCHOOL STUDENTS IN SOLVING TWO VARIABEL LINEAR EQUATION SYSTEM PROBLEM}

\author{
Maria R.D.S.Barreto, Kristoforus D. Djong \\ Universitas Katolik Widya Mandira \\ chardybarreto9721@gmail.com, djongdflores@gmail.com
}

\begin{abstract}
Abstrak: Penelitian ini bertujuan untuk mendeskripsikan kesulitan belajar siswa SMP dalam memecahkan masalah soal sistem persamaan linear dua variabel kelas VIII SMP Negeri 3 Kupang Tengah. Penelitan ini merupakan penelitian deskriptif dengan menggunakan pendekatan kualitatif. Subyek penelitian adalah 2 siswa yang dipilih dari 25 siswa. Subyek penelitian ini dipilih menggunakan pemilihan sampel bertujuan (purposive sample) dimana kedua siswa tersebut masing-masing dengan kemampuan sedang dan rendah. Teknik pengumpulan data yang digunakan tes pemecahan masalah, wawancara dan dokumentasi. Langkah-langkah dalam analisis data adalah indikator Polya, penyajian data dan penarikan kesimpulan. Hasil penelitian dipaparkan sebagai berikut: (a) siswa dengan tingkat kemampuan sedang dalam memecahkan masalah sesuai tahap Polya mampu memahami masalah, akan tetapi siswa belum mampu menyusun rencana penyelesaian, melaksanakan rencana penyelesaian. Namun dalam memeriksa kembali hasil siswa masih meyakinkan diri bahwa hasil pekerjaanya sudah benar. (b) siswa dengan tingkah kemampuan rendah dalam memechkan masalah sesuai dengan tahap Polya mampu memahami masalah, akan tetapi siswa belum mampu menyusun rencana penyelesaian, melaksanakan rencana penyelesaian. Namun dalam memeriksa kembali hasil siswa masih meyakinkan diri bahwa hasil pekerjaanya sudah benar. Hal ini disebabkan siswa tidak mampu membuat konsepkonsep yang berkaitan dengan soal yang diberikan, dan menyusun langkah-langkah penyelesaian yang berkaitan dengan soal yang diberikan agar soal dapat diselesaikan secara sistematis.
\end{abstract}

Kata Kunci: Kesulitan belajar, Memecahkan masalah

Abstract: This purpose of this research is to describe the learning diffliculty Of Junior High School Students in Solving two-variabels linear Equantion System Problems, especially students of grade VIII in public Junior School 3 Of Kupang Tengah. This research with a qualitative approach. The subjects of this research are 2 students, chosen from 25 students. The subjects are chosen using purposive sample method, whom these two students have middling and lowes capasity. The research uses problem solving test, interview and documentation in collecting the datas. The steps of data analysis include polya indictator, data presentation and conclision drawing. The results described as : a) Middling capacity student in solving problems based on Polya steps is able to understand the problem, but still not able to draw a conclusion and doing conclusion yet. The student still convinces himself in rechecking his work that it is correct. b) Lower capacity student in solving problems based on Polya steps is able to undertend the problem but still not able to draw a conclusion and do cunclusion plan yet. The student still convinces himself in recheking his work that it is correct. This happens because the student is not able to create concepts regarding to the given problems and composing conclusion steps regarding to the problems so that the problems can be systematically solved.

Key Words: Learning difficulty, solving problems

Cara Sitasi: Barreto R. D. S. M., \& Djong, D. K., (2019) Profil Kesulitan Belajar Siswa SMP Dalam Memecahkan Masalah Soal Sistem Persamaan Linear Dua Variabel. Asimtot: Jurnal Kependidikan Matematika, "1 "("2”) “119-126”. 
Pengalaman hidup adalah guru terbaik, dimana seorang guru bisa memberikan pengalaman mengajar yang baik dan yang buruk demikian ungkapan klasik. Namun di masa ini pendidikan tidak bisa diabaikan begitu saja sebab pendidikan merupakan pegangan dan penopang bagi hidup setiap orang. Pendidikan menjadi penting untuk diperhatikan karena pendidikan merupakan objek yang sangat luas, ruang lingkupnya mencapai seluruh pengalaman dan pemikiran manusia. Sehingga pada prakteknya proses mendidik itu membawa perubahan, perkembangan dan kemajuan di bidang yang dimaksud (Saduloh, 2004;1).

Pembelajaran matematika merupakan seperangkat rencana dan peraturan mengenai tujuan, isi, dan bahan pelajaran serta cara yang digunakan sebagai pedoman dalam penyelenggaraan kegiatan pembelajaran untuk mencapai tujuan pendidikan. Seperti yang telah dikemukakan di atas tentang arah dari suatu kegitan mendidik, maka pembelajaran matematika sebagai salah satu dari suatu kegiatan mendidik pun diharapkan dan bahkan dituntut untuk membawa perubahan, perkembangan dan kemajuan dalam bidang atau cabang ilmu matematika. Dalam konteks pembelajaran matematika semua usaha yang akan diarahkan kepada pencapaian tujuan kompetensi. Karena itu, pendidik dan peserta didik harus bekerja sama untuk mencapai tujuan tersebut.

Kata belajar bukanlah sesuatu yang baru, sudah sangat dikenal secara luas. Slameto (Djamarah, 2011: 13) mendefinisikan bahwa "belajar merupakan suatu proses usaha yang dilakukan individu untuk memperoleh suatu perubahan tingkah laku yang baru secara keseluruhan, sebagai hasil pengalaman individu itu sendiri dalam interaksi dengan lingkungannya". Sementara Good dan Brophy (Uno, 2015: 15) mendefinisikan bahwa "belajar merupakan suatu proses atau interaksi yang dilakukan seseorang dalam memperoleh sesuatu yang baru dalam bentuk perubahan perilaku sebagai hasil dari pengalaman itu sendiri”. Sedangkan Fajar, Arnie (2015: 10) mendefinisikan bahwa: "belajar adalah suatu proses perubahan dalam diri seseorang yang ditampakkan dalam bentuk peningkatan kualitas dan kuantitas tingkah laku seperti peningkatan pengetahuan, kecakapan, daya pikir, sikap, kebiasaan, dan lain-lain".

Bicara tentang kesulitan belajar, tidak terlepas dari faktor-faktor yang menyebabkan kesulitan belajar. Dalam buku psikologi belajar Ahmadi dan Supriyono (2013: 78) dikatakan bahwa "faktor kesulitan belajar dipengaruhi oleh dua faktor, yaitu faktor internal dan eksternal". Adapun faktor internal meliputi kesiapan fisik dan psikologi. Kesiapan fisik ini penting, mengingat ketika siswa mengalami kelemahan fisik maka saraf sensoris dan metoris akan ikut melemah akibatnya rangsangan yang diterima melalui inderanya tidak dapat diteruskan ke otak. Kesiapan psikologis merupakan kesiapan siswa yang membuat ketegangan dan kenyaman siswa dalam menerimanya pelajar meliputi, intelegensi, bakat, minat, dan motivasi. Faktor eksternal meliputi, lingkungan sosial dan non-sosial.

Pemecahan masalah merupakan bagian dari kurikulum matematika yang sangat penting. Hal ini dikarenakan siswa akan memperoleh pengalaman dalam menggunakan pengetahuan serta keterampilan yang dimiliki untuk menyelesaikan soal yang tidak rutin. Sependapat dengan pernyataan tersebut, Leacher (Wardhani, dkk, 2010:15) 
mendefenisikan pemecahan masalah matematika sebagai "proses menerapkan pengetahuan matematika yang telah diperoleh sebelumnya ke dalam situasi baru yang belum di kenal".

Sedangkan menurut Polya (Siswono, 2008: 36-37) "terdapat empat tahapan penting yang harus ditempuh siswa dalam memecahkan maslaah, yakni memahami masalah, menyusun rencana penyelesaian, melaksanakan rencana penyelesaian, dan memeriksa kembali. Melalui tahapan yang terorganisir tersebut, siswa akan memperoleh hasil dan manfaat yang optimal dari pemecahan masalah".

Metode Penelitian

Jenis penelitian ini adalah penelitian deskriptif dengan pendekatan kualitatif. Karena dalam penelitian ini, peneliti bertujuan mendeskripsikan kesulitan belajar siswa SMP dalam memecahkan masalah matematika.

Subjek dalam penelitian ini yaitu 2 orang siswa kelas VIII. Pemilihan subjek dilakukan melalui hasil nilai ulangan siswa kelas VIII kemudian dipilih 2 orang yang siswa dengan kemampuan sedang, dengan siswa yang memiliki kemampuan rendah. Tingkat kemampuan matematika dapat dilihat pada tabel berikut:

Table 3.1 Kriteria Tingkat Kemampuan

\begin{tabular}{lc}
\multicolumn{2}{c}{ Matematika } \\
\hline Tingkat Kemampuan & Skor \\
\hline Sedang & 70 \\
& $\leq$ skor \\
& $<95$ \\
\hline Rendah & $0 \leq$ skor \\
& $<70$ \\
\hline Instrumen utama pada penelitian ini \\
adalah peneliti sendiri, karena dalam \\
penelitian ini peneliti berperan
\end{tabular}

mengumpulkan, menganalisis, dan menginterprestasikan data.

Instrumen pendukung pada penelitian ini, instrumen pendukungnya adalah Tes pemecahan masalah Pedoman wawancara.

Teknik Pengumpulan Data dalam penelitian ini adalah: Tes Pemecahan Masalah, Wawancara, Dokumentasi.

\section{Hasil Penelitian dan Pembahasan}

\section{Hasil}

Hasil Pengembangan Instrumen Tes Pemecahan Masalah (TPM). Istrumen tes pemecahan masalah dalam penelitian ini bertujuan untuk mengetahui gambaran kesulitan belajar siswa SMP dalam memecahkan masalah soal sistem persamaan linear dua variabel. Tes pemecahan masalah ini telah dikonsultasikan dengan dosen pembimbing dan layak digunakan dengan perbaikkan. Tes pemecahan masalah ini terdiri dari 1 butir soal, namun untuk keperluan triangulasi tes ini dibuat 2 dengan kondisi yang setara.

Sebelum soal TPM digunakan soal tersebut terlebih dahulu telah divalidasi oleh dosen dan guru mata pelajaran matematika. Oleh karena itu, tes pemecahan masalah ini dapat digunakan untuk pengambilan data untuk mengetahui gambaran kesulitan belajar siswa SMP dalam memecahkan soal sistem persamaan linear dua variabel. Pengujian soal tersebut, ditekankan pada validitas isi yang berkaitan dengan materi dan validitas susunan yang berkaitan dengan konstruksi dan bahasa yang digunakan. Uji validitas dilakukan dengan divalidasi oleh 1 orang dosen dan 1 guru matematika. Hasil validitas dapat dilihat pada tabel 4.1 di bawah ini. 


\begin{tabular}{|c|c|}
\hline $\begin{array}{c}\text { Hasil analisis } \\
\text { berkemampuan sedang (JS } \\
\text { Tabel } 4.2 \text { (Paparan Dan } \\
\text { Dalam Memahami }\end{array}$ & $\begin{array}{l}\text { data subyek } \\
\text { Validasi Data JS } \\
\text { Masalah) }\end{array}$ \\
\hline $\begin{array}{l}\text { Hasil wawancara TPM } \\
1\end{array}$ & $\begin{array}{l}\text { Hasil wawancara } \\
\text { TPM } 2\end{array}$ \\
\hline $\begin{array}{l}\text { JS menyebutkan apa } \\
\text { yang diketahui (JS104) }\end{array}$ & $\begin{array}{l}\text { JS menyebutkan } \\
\text { apa yang } \\
\text { diketahui } \\
\text { (JS204) }\end{array}$ \\
\hline $\begin{array}{l}\text { JS menyebutkan apa } \\
\text { yang } \\
(\text { JS105) }\end{array}$ & $\begin{array}{l}\text { JS menyebutkan } \\
\text { apa yang } \\
\text { ditanyakan } \\
\text { (JS205) }\end{array}$ \\
\hline
\end{tabular}

Berdasarkan paparan dan data pada tabel 4.2 di atas, dapat disimpulkan ada konsistensi data subyek JS dalam memahami masalah. TPM 1 dan TPM 2. Oleh karena itu data subyek JS dalam memahami masalah TPM 1 merupakan data yang valid. Penyimpulan data subyek (JS) dalam memahami masalah Subyek JS memahami masalah dengan membaca soal. Dari membaca soal subyek JS dapat menyebutkan apa yang diketahui (JS104) dan apa yang ditanyakan (JS105). Jadi dapat dikatakan subyek JS tidak mengalami kesulitan dalam memahami masalah.

Tabel 4.3 (Paparan Dan Validasi Data JS Dalam Merencanakan penyelasaian)

\begin{tabular}{ll}
\hline Hasil wawancara TPM & Hasil \\
1 & wawancara \\
& TPM 2 \\
\hline Subyek memulai & Subyek \\
merencanakan dengan & memulai \\
memisalkan penggaris & merencanakan \\
= x dan penghapus = y & dengan \\
(JS108,JS109) & memisalkan \\
& penggaris = x \\
& dan penghapus \\
& $=$ y \\
& $(J S 208, J S 209)$ \\
\hline
\end{tabular}

\begin{tabular}{|c|c|}
\hline $\begin{array}{lr}\text { Subyek } & \text { tidak } \\
\text { memahami } & \text { mengapa } \\
\text { harus } & \text { dimisalkan } \\
\text { dengan x dan y (JS109) }\end{array}$ & $\begin{array}{l}\text { Subyek tidak } \\
\text { memahami } \\
\text { mengapa harus } \\
\text { dimisalkan } \\
\text { dengan } \mathrm{x} \text { dan } \mathrm{y} \\
(J S 209)\end{array}$ \\
\hline $\begin{array}{lr}\text { Subyek tidak dapat } \\
\text { membuat rencana } \\
\text { penyelesaian yang } \\
\text { lengkap (JS111,JS112) }\end{array}$ & $\begin{array}{l}\text { Subyek tidak } \\
\text { dapat membuat } \\
\text { rencana } \\
\text { penyelesaian } \\
\text { yang lengkap } \\
(J S 213, J S 214) \text {. }\end{array}$ \\
\hline
\end{tabular}

Berdasarkan paparan dan data validasi data pada tabel 4.3 di atas yang diungkapkan subyek JS cendrung konsisten atau tetap dari TPM 1 dan TPM 2. Sehingga dapat dikatakan bahwa data subyek JS dalam merencanakan penyelesaian TPM 1 adalah valid. Penyimpulan data subyek (JS) dalam merencanakan penyelesaian. Subyek JS tidak dapat membuat rencana penyelesaian secara lengkap, subyek tidak memahami makna simbol dalam rencana penyelesaian. Jadi subyek mengalami kesulitan dalam merencanakan penyelesaian.

Tabel 4.4 (Paparan Dan Validasi Data JS Dalam Melaksanakan rencana)

\begin{tabular}{|c|c|}
\hline $\begin{array}{l}\text { Hasil } \\
\text { TPM } 1\end{array}$ & $\begin{array}{l}\text { Hasil } \\
\text { TPM } 2\end{array}$ \\
\hline $\begin{array}{l}\text { Subyek tidak mampu } \\
\text { menjelaskan maksud } \\
\text { dari persamaan linear } \\
\text { dua variabel } 4 x+2 y= \\
10.000(\mathrm{JS} 116)\end{array}$ & $\begin{array}{l}\text { Subyek mampu } \\
\text { menjelaskan bentuk } \\
\text { persamaan linear dua } \\
\text { variabel (JS215). }\end{array}$ \\
\hline $\begin{array}{lr}\text { Subyek } & \text { dapat } \\
\text { menuliskan } & \text { kalimat } \\
\text { matematika } & \text { dengan } \\
\text { benar, namun subyek } \\
\text { tidak } \\
\text { memahami apa yang } \\
\text { ditulis (JS117, JS118) }\end{array}$ & $\begin{array}{lr}\text { Subyek } & \text { dapat } \\
\text { menuliskan } & \text { kalimat } \\
\text { matematika dengan } \\
\text { benar. } & \text { Namum } \\
\text { subyek tidak mampu } \\
\text { memahami apa yang } \\
\text { ditulis } \\
(\text { JS217,JS218) }\end{array}$ \\
\hline
\end{tabular}




\begin{tabular}{|c|c|}
\hline $\begin{array}{l}\text { Subyek menemukan } \\
\text { cara mengeliminasi } \\
\text { nilai x (JS120,JS122) } \\
\text { namun subyek belum } \\
\text { tepat dalam } \\
\text { menentukan nilai y } \\
(\mathrm{JS} 122, \mathrm{JS} 124)\end{array}$ & $\begin{array}{l}\text { Subyek memahami } \\
\text { cara mengeliminasi } \\
\text { nilai } \\
(\mathrm{JS} 220, \mathrm{JS} 223) \text {. } \\
\text { Namun subyek } \\
\text { belum tepat dalam } \\
\text { menentukan nilai y } \\
(\mathrm{JS} 224, \mathrm{JS} 225, \mathrm{JS} 226)\end{array}$ \\
\hline $\begin{array}{l}\text { Subyek } \\
\text { mensubtitusikan nilai } \\
\text { y ke dalam } \\
\text { persamaan } 32 \mathrm{x}+16 \mathrm{y} \\
=\quad 80.000 \\
(\mathrm{JS} 125, \mathrm{JS} 128) \text {. } \\
\text { Namun subyek tidak } \\
\text { dapat menentukan } \\
\text { nilai x dengan benar } \\
(\text { JS129) }\end{array}$ & $\begin{array}{l}\text { Subyek memahami } \\
\text { bagaimana cara } \\
\text { mengsubtitusikan } \\
\text { (JS228,JS229). } \\
\text { Namun dalam } \\
\text { penyelesaiannya } \\
\text { untuk menentukan } \\
\text { nilai x kurang tepat } \\
\text { (JS230, JS233) }\end{array}$ \\
\hline $\begin{array}{l}\text { Berdasarkan paparan d } \\
\text { pada tabel } 4.4 \text { di ata } \\
\text { subyek JS cendrung ko } \\
\text { TPM } 1 \text { dan TPM } 2 \text {. Seh } \\
\text { bahwa data subyek JS } \\
\text { rencana penyelesaian } \\
\text { Penyimpulan data } \\
\text { melaksanakan rencana } \\
\text { mampu menjelaskan m } \\
\text { linear dua variabel, Sub } \\
\text { kalimat matematika d } \\
\text { subyek tidak mampu } \\
\text { ditulis, subyek } \\
\text { mengeliminasi nilai x } \\
\text { tepat dalam menentul } \\
\text { mengsubtitusikan nilai } \\
\text { 32x + 16y = 80.000. } \\
\text { dapat menentukan nilai } \\
\text { dapat dikatakan sub } \\
\text { kesulitan dalam melaks } \\
\text { Tabel 4.5 Paparan D } \\
\text { Dalam Memeriksa kem }\end{array}$ & $\begin{array}{l}\text { an data validasi data } \\
\text { yang diungkapakan } \\
\text { nsisten atau tetap dari } \\
\text { ingga dapat dikatakan } \\
\text { dalam melaksanakan } \\
\text { TPM } 1 \text { valid. } \\
\text { subyek JS dalam } \\
\text { Subyek JS dapat } \\
\text { aksud dari persamaan } \\
\text { yek dapat menuliskan } \\
\text { engan benar, namun } \\
\text { memahami apa yang } \\
\text { menentukan cara } \\
\text { namun subyek belum } \\
\text { kan nilai y, subyek } \\
\text { y ke dalam persamaan } \\
\text { Namun subyek tidak } \\
\text { x dengan benar. Jadi } \\
\text { yek JS mengalami } \\
\text { anakan rencana. } \\
\text { an Validasi Data JS } \\
\text { bali }\end{array}$ \\
\hline $\begin{array}{l}\text { Hasil wawancara } \\
\text { TPM } 1\end{array}$ & $\begin{array}{l}\text { Hasil } \quad \text { wawancara } \\
\text { TPM } 2\end{array}$ \\
\hline
\end{tabular}

\begin{tabular}{lrlr}
\hline Subyek memeriksa & Subyek mampu \\
kembali dengan & memeriksa dan \\
melihat pekerjaan & menjelaskankembali \\
yang sudah dibuatnya & apa yang dikerjakan \\
$(J S 134)$ & & $(J S 238)$ \\
Subyek mengatakan & Subyek mengatakan \\
penyelesaian- nya & penyelesaian- nya \\
sudah pas $(J S 134)$ & sudah pas (JS238) \\
\hline Berdasarkan paparan dan data validasi data
\end{tabular}

Berdasarkan paparan dan data validasi data pada tabel 4.5 di atas yang diungkapakan subyek JS cendrung konsisten atau tetap dari TPM 1 dan TPM 2. Sehingga dapat dikatakan bahwa data subyek JS dalam memeriksa kembali TPM 1 adalah valid. Penyimpulan data subyek JS dalam memeriksa kembali Subyek JS memeriksa dan menjelaskan kembali dengan melihat pekerjaan yang sudah dibuatnya, subyek JS mengatakan penyelesaianya sudah pas (JS134). Jadi dapat dikatakan subyek JS yakin dengan apa yang sudah dikerjakannya.

Hasil analisis data subyek berkemampuan rendah (FT)

Tabel 4.6 (Paparan Dan Validasi Data FT Dalam memahami masalah)

\begin{tabular}{|c|c|c|}
\hline $\begin{array}{l}\text { Hasil } \\
\text { TPM } 1\end{array}$ & wawancara & $\begin{array}{l}\text { Hasil wawancara } \\
\text { TPM } 2\end{array}$ \\
\hline $\begin{array}{l}\text { Subyek } \\
\text { menyebutkan }\end{array}$ & $\begin{array}{l}\text { FT } \\
\text { apa }\end{array}$ & $\begin{array}{lc}\text { Subyek } & \text { FT } \\
\text { menyebutkan } & \text { apa }\end{array}$ \\
\hline $\begin{array}{l}\text { yang } \\
\text { (FT106) }\end{array}$ & diketahui & $\begin{array}{l}\text { yang diketahui } \\
\text { (FT206) }\end{array}$ \\
\hline $\begin{array}{l}\text { Subyek } \\
\text { menyebutkan }\end{array}$ & $\begin{array}{r}\text { FT } \\
\text { an } \quad \text { apa }\end{array}$ & $\begin{array}{lc}\text { Subyek } & \text { FT } \\
\text { menyebutkan } & \text { apa }\end{array}$ \\
\hline $\begin{array}{ll}\text { yang } & \text { d } \\
(\text { FT107) } & \end{array}$ & ditanyakan & $\begin{array}{l}\text { yang ditanyakan } \\
\text { (FT207) }\end{array}$ \\
\hline
\end{tabular}

Berdasarkan paparan dan data validasi data pada tabel 4.6 di atas yang diungkapakan subyek FT cendrung konsisten atau tetap dari TPM 1 dan TPM 2. Sehingga dapat dikatakan bahwa data subyek FT dalam memahami masalah adalah valid. Penyimpulan data subyek FT dalam Memahami Masalah subyek 
FT memahami masalah dengan membaca soal. Dari membaca soal subyek FT dapat menyebutkan apa yang diketahui (FT106) dan apa yang ditanyakan (FT107). Jadi dapat dikatakan subyek FT tidak mengalami kesulitan dalam memahami masalah

Tabel 4.7 (Paparan Dan Validasi Data FT Dalam merencanakan penyelesaian)

\begin{tabular}{ll}
\hline Hasil & Hasil \\
wawancara & wawancara \\
TPM 1 & TPM 2 \\
\hline Subyek & Subyek \\
memulai & memulai \\
merencanakan & merencanakan \\
dengan & dengan \\
memisalkan & memisalkan \\
penggaris = x & penggaris = x \\
dan penghapus & dan penghapus \\
= y (FT110) & $=$ y (FT210) \\
\hline Subyek tidak & Subyek tidak \\
memahami & memahami \\
mengapa harus & mengapa harus \\
dimisalkan & dimisalkan \\
dengan x dan y & dengan x dan y \\
(FT111) & (FT211) \\
\hline Subyek tidak & Subyek tidak \\
dapat membuat & dapat membuat \\
rencana & rencana \\
penyelesaian & penyelesaian \\
yang lengkap & yang lengkap \\
(FT112) & (FT212) \\
\hline
\end{tabular}

Berdasarkan paparan dan data validasi data pada tabel 4.7 di atas yang diungkapakan subyek FT cendrung konsisten atau tetap dari TPM 1 dan TPM 2. Sehingga dapat dikatakan bahwa data subyek FT dalam merencanakan penyelesaian adalah valid. Penyimpulan data subyek FT dalam merencanakan penyelesaian subyek FT tidak dapat membuat rencana penyelesaian secara lengkap, subyek tidak memahami makna simbol dalam rencana penyelesaian. Jadi subyek mengalami kesulitan dalam merencanakan masalah. .

Tabel 4.8 (Paparan Dan Validasi Data FT Dalam melaksanakan rencana)

\begin{tabular}{|c|c|}
\hline $\begin{array}{l}\text { Hasil wawancara } \\
\text { TPM } 1\end{array}$ & $\begin{array}{l}\text { Hasil } \\
\text { wawancara TPM } \\
2\end{array}$ \\
\hline $\begin{array}{l}\text { Subyek mampu } \\
\text { menjelaskan dan } \\
\text { menuliskan } \\
\text { persamaan (FT113) }\end{array}$ & $\begin{array}{l}\text { Subyek mampu } \\
\text { menjelaskan dan } \\
\text { menuliskan } \\
\text { persamaan } \\
\text { (FT213) }\end{array}$ \\
\hline $\begin{array}{lr}\text { Subyek mampu } \\
\text { mengeliminasi } \\
\text { persamaan yang } \\
\text { telah dibuat. } \\
\text { Namun subyek } \\
\text { tidak } \quad \text { bisa } \\
\text { menjelaskan hasil } \\
\text { pekerjaannya } \\
(\text { FT114, FT117) }\end{array}$ & $\begin{array}{l}\text { Subyek mampu } \\
\text { mengeliminasi } \\
\text { persamaan yang } \\
\text { telah dibuat. } \\
\text { Namun subyek } \\
\text { tidak bisa } \\
\text { menjelaskan } \\
\text { hasil } \\
\text { pekerjaannya } \\
(F T 216, F T 218)\end{array}$ \\
\hline
\end{tabular}

Berdasarkan paparan dan data validasi data pada tabel 4.8 di atas yang diungkapakan subyek FT cendrung konsisten atau tetap dari TPM 1 dan TPM 2. Sehingga dapat dikatakan bahwa data subyek FT dalam melaksanakan rencana adalah valid. Penyimpulan data subyek FT dalam melaksanakan rencana subyek FT mampu menjelaskan dan menuliskan persamaan (FT113), Subyek mampu mengeliminasi persamaan yang telah dibuat. Namun subyek tidak bisa menjelaskan hasil pekerjaannya (FT114, FT117). Jadi subyek FT mengalami kesulitan dalam melaksanakan rencana.

Tabel 4.9 (Paparan Dan Validasi Data FT Dalam memeriksa kembali)

\begin{tabular}{lll}
\hline Hasil wawancara & Hasil \\
TPM 1 & wawancara TPM \\
& 2
\end{tabular}

Subyek memeriksa Subyek 


\begin{tabular}{ll}
\hline kembali dengan & memeriksa \\
melihat & kembali dengan \\
pekerjaanya yang & melihat \\
sudah dibuatnya & pekerjaanya \\
(FT124) & yang sudah \\
& dibuatnya \\
& (FT225) \\
\hline Subyek & Subyek \\
mengatakan & $\begin{array}{l}\text { mengatakan } \\
\text { penyelesaian- } \\
\text { sudah pas (FT124) }\end{array}$ \\
& nya sudah pas \\
& (FT224) \\
\hline
\end{tabular}

Berdasarkan paparan dan data validasi data pada tabel 4.9 di atas yang diungkapakan subyek FT cendrung konsisten atau tetap dari TPM 1 dan TPM 2. Sehingga dapat dikatakan bahwa data subyek FT dalam memeriksa kembali adalah valid. Penyimpulan data subyek FT dalam memeriksa kembali subyek FT memeriksa dan menjelaskan kembali pekerjaan yang sudah dibuatnya, subyek FT mengatakan penyelesaianya sudah pas (FT124). Jadi dapat dikatakan subyek FT yakin dengan apa yang sudah dikerjakannya.

\section{Simpulan dan Saran}

\section{Simpulan}

Berdasarkan hasil penelitian yang dikemukakan oleh peneliti, maka dapat disimpulkan kesulitan belajar siswa SMP dalam memecahkan masalah soal sistem persamaan linear dua variabel sebagai berikut: Siswa dengan tingkat berkemampuan sedang dalam memecahkan masalah sesuai tahap Polya mampu memahami masalah, akan tetapi siswa belum mampu menyusun rencana penyelesaan, melaksanakan rencana penyelesaian, dan memeriksa kembali hasil. Hal ini disebabkan siswa tidak mampu membuat konsep-konsep yang berkaitan dengan soal yang diberikan, dan meyusun langkah-langkah penyelesaian yang berkaitan dengan soal yang diberikan agar soal dapat diselesaikan secara sistematis.

Siswa dengan tingkat berkemampuan rendah dalam memecahkan masalah sesuai tahap Polya mampu memahami masalah, akan tetapi siswa belum mampu menyusun rencana penyelesaan, melaksanakan rencana penyelesaian, dan memeriksa kembali hasil. Hal ini disebabkan siswa tidak mampu membuat konsep-konsep yang berkaitan dengan soal yang diberikan, dan meyusun langkah-langkah penyelesaian yang berkaitan dengan soal yang diberikan agar soal dapat diselesaikan secara sistematis.

\section{Saran}

Berdasarkan hasil penelitian yang dilakukan dan kesimpulan diatas maka saran yang dapat di peneliti kemukaan adalah Bagi siswa dalam melakukan pembelajaran matematika siswa sebaiknya lebih serius dan memiliki motivasi belajar yang tinggi karena dalam belajar matematika siswa diarahkan agar tidak mengalami kesulitan belajar

Bagi guru Dalam mengajar materi sistem persamaan linear dua variabel di kelas guru hendaknya memperhatikan kemampuan yang dimiliki siswa, dengan cara mengetahui tingkat kesulitan belajar siswa agar guru dapat merancang kegiatan pembelajaran dalam memecahkan masalah matematika. Hal ini disebabkan karena jika siswa diajarkan materi yang diatas tingkat berpikirnya, maka akan dikhawatirkan siswa merasa kesulitan dalam memahami materi tersebut.

Bagi sekolah dalam rangka perbaikan dan peningkatan mutu pembelajaran matematika, salah satunya adalah dalam kesulitan belajar siswa dalam memecahkan masalah matematika. 


\section{Daftar Pustaka}

Sadulloh, U. (2014). Pedagogik (ilmu mendidik). Bandung: Alfabeta.

Djamarah, S. (2002). Psikologi Belajar.PT.Ribeka cipta Jakarta : Guru Dan Anak Didik Dalam Interaksi Edukatif Suatu Pendekatan Teoritis Psikologis. Ribeka Cipta:Jakarta.

Fajar, A (2015). Analisis Deskriptif Faktor Penyebab Kesulitan Belajar Mata Pelajaran Matematika Di SMA Negeri 8 Purworejo Tahun Pelajaran 2012/2013. Yogyakarta: diunduh dari suhascarya@yahoo.co.id.

Ahmadi, A. (2013). Psikologi Belajar. Jakarta Rineka Cipta.

Sadulloh, U. (2014). Pedagogik. Jurnal Pendidikan (ilmu mendidik) . Bandung: Alfabeta.

Siswono, T.Y.E. (2008). Mode Pembelajaran Matematika Berbasis Pengajuan Dan Pemecahan Masalah Untuk Meningkatkan Kemampuan Berpikir Kreatif. Penerbit Unesa University Press.

Uno. (2015). Psikologi Belajar. Jakarta: Rineka Cipta.

Wardhani S. (2010). Pembelajaran Kemampuan Pemecahan Masalah Matematika di SD. Yogyakarta: PPPPTK. 